\title{
Transformational improvement in quality care and health systems: the next decade
}

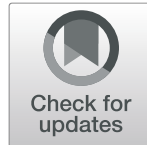

Jeffrey Braithwaite ${ }^{*}$ (D), Charles Vincent ${ }^{2}$, Ezequiel Garcia-Elorrio ${ }^{3}$, Yuichi Imanaka $^{4}$, Wendy Nicklin ${ }^{5}$, Sodzi Sodzi-Tettey ${ }^{6}$ and David W. Bates ${ }^{7}$

\begin{abstract}
Background: Healthcare is amongst the most complex of human systems. Coordinating activities and integrating newer with older ways of treating patients while delivering high-quality, safe care, is challenging. Three landmark reports in 2018 led by (1) the Lancet Global Health Commission, (2) a coalition of the World Health Organization, the Organisation for Economic Co-operation and Development and the World Bank, and (3) the National Academies of Sciences, Engineering and Medicine of the United States propose that health systems need to tackle care quality, create less harm and provide universal health coverage in all nations, but especially low- and middle-income countries. The objective of this study is to review these reports with the aim of advancing the discussion beyond a conceptual diagnosis of quality gaps into identification of practical opportunities for transforming health systems by 2030.

Main body: We analysed the reports via text-mining techniques and content analyses to derive their key themes and concepts. Initiatives to make progress include better measurement, using the capacities of information and communications technologies, taking a systems view of change, supporting systems to be constantly improving, creating learning health systems and undergirding progress with effective research and evaluation. Our analysis suggests that the world needs to move from 2018, the year of reports, to the 2020s, the decade of action. We propose three initiatives to support this move: first, developing a blueprint for change, modifiable to each country's circumstances, to give effect to the reports' recommendations; second, to make tangible steps to reduce inequities within and across health systems, including redistributing resources to areas of greatest need; and third, learning from what goes right to complement current efforts focused on reducing things going wrong. We provide examples of targeted funding which would have major benefits, reduce inequalities, promote universality and be better at learning from successes as well as failures.

Conclusion: The reports contain many recommendations, but lack an integrated, implementable, 10-year action plan for the next decade to give effect to their aims to improve care to the most vulnerable, save lives by providing high-quality healthcare and shift to measuring and ensuring better systems- and patientlevel outcomes. This article signals what needs to be done to achieve these aims.
\end{abstract}

Keywords: Health systems, Patient safety, Quality of care, Universal health coverage, Low-, middle- and highincome countries

\footnotetext{
* Correspondence: jeffrey.braithwaite@mq.edu.au

${ }^{1}$ Centre for Healthcare Resilience and Implementation Science, Australian

Institute of Health Innovation, Macquarie University, Level 6, 75 Talavera road,

North Ryde, NSW 2113, Australia

Full list of author information is available at the end of the article
}

(c) The Author(s). 2020 Open Access This article is licensed under a Creative Commons Attribution 4.0 International License, which permits use, sharing, adaptation, distribution and reproduction in any medium or format, as long as you give appropriate credit to the original author(s) and the source, provide a link to the Creative Commons licence, and indicate if changes were made. The images or other third party material in this article are included in the article's Creative Commons licence, unless indicated otherwise in a credit line to the material. If material is not included in the article's Creative Commons licence and your intended use is not permitted by statutory regulation or exceeds the permitted use, you will need to obtain permission directly from the copyright holder. To view a copy of this licence, visit http://creativecommons.org/licenses/by/4.0/ The Creative Commons Public Domain Dedication waiver (http://creativecommons.org/publicdomain/zero/1.0/) applies to the data made available in this article, unless otherwise stated in a credit line to the data. 
We need health systems that enable the provision of higher-quality and safer healthcare, reflect population needs, and facilitate better assessment and management of population health. Three major reports in 2018 argue for such systems transformation [1-3]. Can it be achieved?

\section{Background}

The organisation and provision of healthcare is changing. Looking back over the centuries, physicians and other healthcare professionals had rudimentary practices, patients had modest expectations and there was no real health system as clinicians were independent providers. However, by the late twentieth century, healthcare had evolved to become the most complex of human endeavours [4]. The range of patient types and conditions, procedures, tests, technologies available, drugs, specialist workers and settings in which care was delivered, even in low- and middle-income countries (LMICs) with modest resources, grew exponentially $[5,6]$. This demanded extensive supporting structures and coordination.

Fast forward to the third decade of the twenty-first century. We now have sophisticated information and telecommunications technologies, genomics, precision medicine, artificial intelligence, advanced pharma and unrivalled devices to support care, all of which are adding more capacity to deliver better treatment and interventions [7]. While LMICs have some access to these, they must do things less expensively-for example, by using mobile technology and microgrids rather than large computer systems. These new additions to the caring environment confer benefits to patients yet are immeasurably increasing systems complexity [8], and accelerating the need to be even better at coordination so all in the healthcare orchestra sing from the same song sheet.

\section{Major reports in 2018}

Three recent milestone contributions address the issue of quality of care primarily as it affects the developing world yet with key messages for all health systems, developing or mature [1-3]. They offer recommendations for how to create better delivery systems and improve care quality. They each aspire, amongst all this complexity, to put care on an improvement gradient-to make it safer, of higher quality, and more responsive to demands across time. They also suggest that systems are becoming tougher to manage and coordinate, and enhancement of care and care settings, from policy to management to practice, is very hard to achieve. In this article, we analyse these reports individually and as a whole, and, as Academicians of the International Academy of Quality and Safety (IAQS) established by the
International Society for Quality in Health Care (ISQua), we aim to describe the commonalities and differences and establish the platform from which we can improve care internationally. We begin with a synthesis of the main thrust of the arguments in the three reports.

The Lancet report (Box 1) makes a set of recommendations for how national governments and funding partners can take the lead in creating better, more caring, less harmful systems. It argues that a core enabler for achieving these goals will be a research agenda to underpin the key advances which need to be achieved (see Box 1 for a summary).

The WHO/OECD/World Bank report (Box 2) envisages widespread enabling action by governments, health systems and citizens, patients and health workers. It suggests that these bodies and groups should be encouraged to collaborate and conspire to deliver improved care across-the-board (see Box 2 for a summary).

The National Academies' report (Box 3) represents a clarion call for more research, better measurement and concerted international efforts. It suggests creating a learning health system which contrasts with today's forgetting system, and encourages people to think in

Box 1: The Lancet Global Health Commission report: High-Quality Health Systems in the Sustainable Goals Era: Time for a Revolution [3]

- Looks across low-, middle-, and high-income countries.

- Acknowledges patients in health systems in less wealthy countries, and vulnerable populations, need priority attention.

- Indicates that the lives of millions of people could be saved or enhanced if high-quality health systems were in place.

- Contends that delivery systems need to contribute, measure and report on what matters-effective care provided on the front lines, meeting patients' not just providers' needs, and supplying high-quality care to the maximum extent achievable.

- Summarises what is needed-more resources in the right places, better use of existing resources and providers taking a systems perspective, adopting things known to deliver better care, e.g. adherence to evidence based guidelines, use of Information and Communications Technology (ICT) known to improve decision-making and treatment, and scaling up good practices regionally and nationally.

- Advances universal actions, chief of which are to: govern for quality; redesign service delivery to optimise quality; transform the health workforce; and stimulate population demand for high-quality care. 


\section{Box 2: WHO/OECD/World Bank report, Delivering Quality Health Services: A Global Imperative for Universal Health Coverage [2]}

- Argues for universal health coverage (UHC) for every health system such that all citizens have access to the range of quality health services they need as affordably as possible.

- Laments the low quality of care and poor adherence to clinical practice guidelines, even in high-income countries; and notes that it is far worse in low-income countries.

- Observes that there is lots of variation in outcomes across health systems, and therefore much scope to improve; for instance, screening, prevention, immunisation and community support vary across countries and are sometimes at such poor levels that large numbers in the population suffer.

- Expresses concern that sub-optimal clinical practices are common across the spectrum of public, private, primary and acute care in many countries.

- Articulates the need for a highly trained workforce, excellent service provision from facilities, safe and effective use of technology, drugs, and devices, better use of health information systems, and financing mechanisms that incentivise quality care and continuous improvement.

- Specifies a range of interventions to improve care and supports the scale up of successful interventions.

systems terms rather than in silos or episodes (see Box 3 for a summary).

\section{Method}

To understand more deeply the tenor and extent of the reports, we conducted an analysis of them using textmining software provided by Leximancer 4.51, an automated content analysis computer program [9, 10]. Leximancer facilitates the interrogation of texts-words, and word segments-and creates a thesaurus of significant terms, known as textual concepts. The software allows the examination of the connectivity and relationship between concepts in large text documents. Groups of the most highly connected concepts are referred to as themes. Leximancer produces a ranked list of themes and a visual map of their connections, providing details of both the strength of a concept as it recurs within the text and the extent of connections to other concepts. Leximancer's automated interrogation of documents can be applied to PDF and word processed documents. Essentially, the Leximancer program breaks down textual material into its key categories (themes, concepts) in order to visualise and quantify the text $[10,11]$.
Box 3: The National Academies of Sciences, Engineering and Medicine report: Crossing the Global Quality Chasm: Improving Health Care Worldwide [1]

- Sounds alarm at the harm healthcare creates, the current state of caring systems, the scale of the problems and the poor performance of many health systems in not delivering high-quality care, especially to LMICs.

- Sees core needs for much better monitoring and evaluation systems, customer satisfaction surveys, research and evaluation.

- Indicates that part of the solution rests in training people to be better at systems thinking and factoring in the complexity of the system.

- Argues in favour of patient centred thinking and wants to focus on optimising the patient journey.

- Asks for reformers not to forget that much care that takes place in informal settings by family and friends, outside of the formal structures and delivery systems.

- Articulates a problem not covered by other systems reports sufficiently well, namely corruption and its deleterious impact on healthcare.

- Argues for embedding quality within UHC and implores everyone everywhere to establish a culture of continuous improvement.

\section{Results}

Figures 1, 3, 5 and 7 provide the Leximancer maps of themes and concepts, accompanied by the frequency of their highest recurring themes (Figs. 2, 4, 6 and 8).

In the first visual diagram (Fig. 1), eleven themes (circles) represent the content of the three reports in broad outline (see Fig. 2 for theme frequency summary of Fig. 1).

Across the three reports, "health", "care", "systems", "Quality", "countries" and "examples" are the most frequently occurring themes. These key themes suggest the reports are largely focused on the quality of care provided by health systems within and across various countries, with multiple examples provided. The graphical representation of Fig. 1 depicted in Fig. 2 shows the strength of the recurrences ("hits") of each theme.

In Fig. 3, thirteen themes (circles) represent the content of the Lancet report in more detail (see Fig. 4 for theme frequency summary of Fig. 3).

Over the pages of the Lancet report, "health", "system", "care", "people", "data" and "countries" are the most frequently occurring themes. These key themes show how the report is mostly focused on people and data in healthcare systems across all countries of the world. 


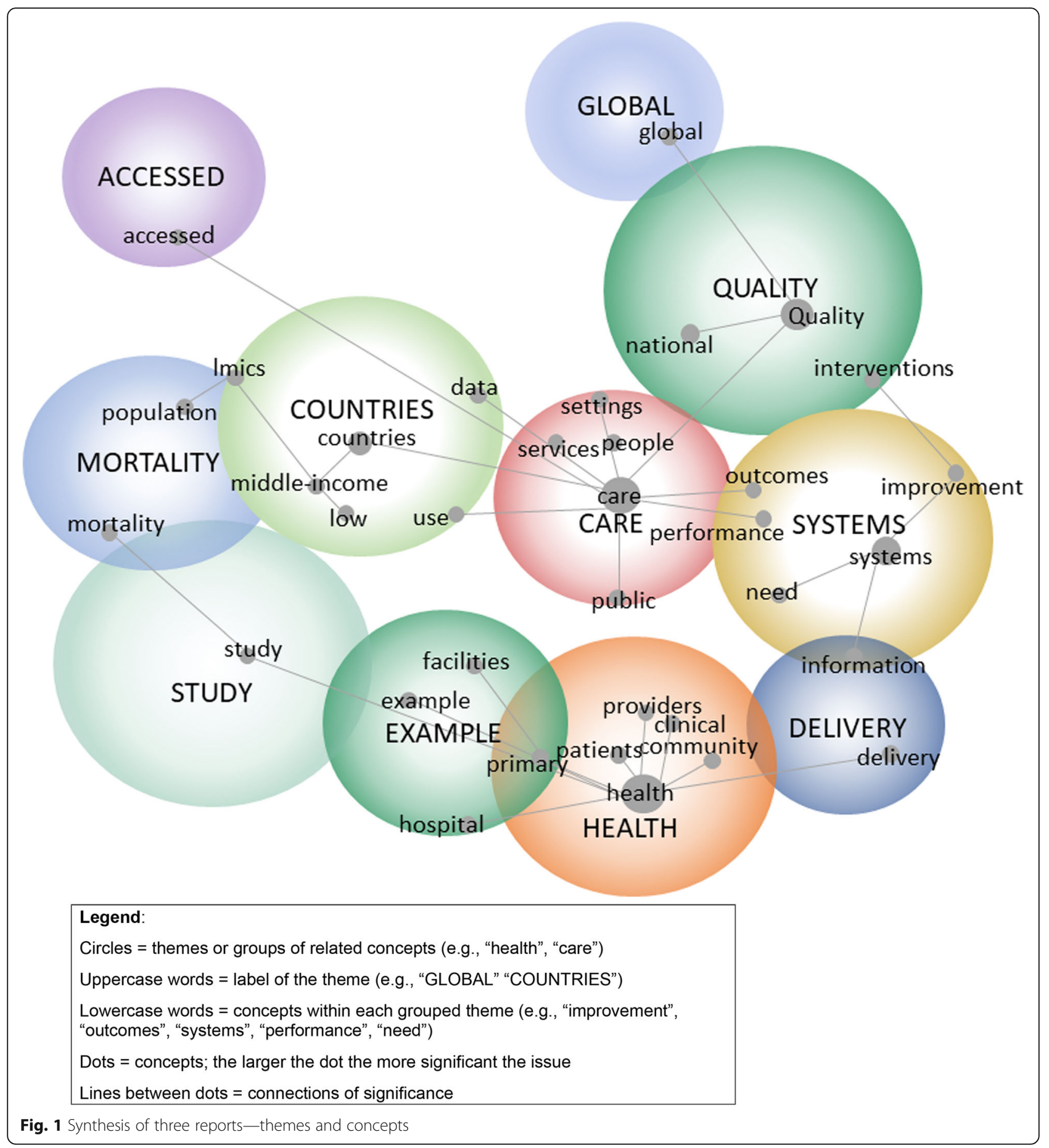

In Fig. 5, nine themes (circles) represent the content of the WHO/OECD/World Bank report in more detail (see Fig. 6 for theme frequency summary of Fig. 5).

Across the WHO/OECD/World Bank report, "health", "care", "quality", "improvement", "universal" and "accessed" are the most frequently occurring themes. These key themes suggest the report is mostly focused on the improvement of quality of care and access to care, particularly universal health coverage.

In Fig. 7, thirteen themes represent the content of the National Academies' report in more detail (see Fig. 8 for theme frequency summary of Fig. 7).

For this report, "providers", "quality", "systems", "use" and "patients" are the most frequently occurring themes. 


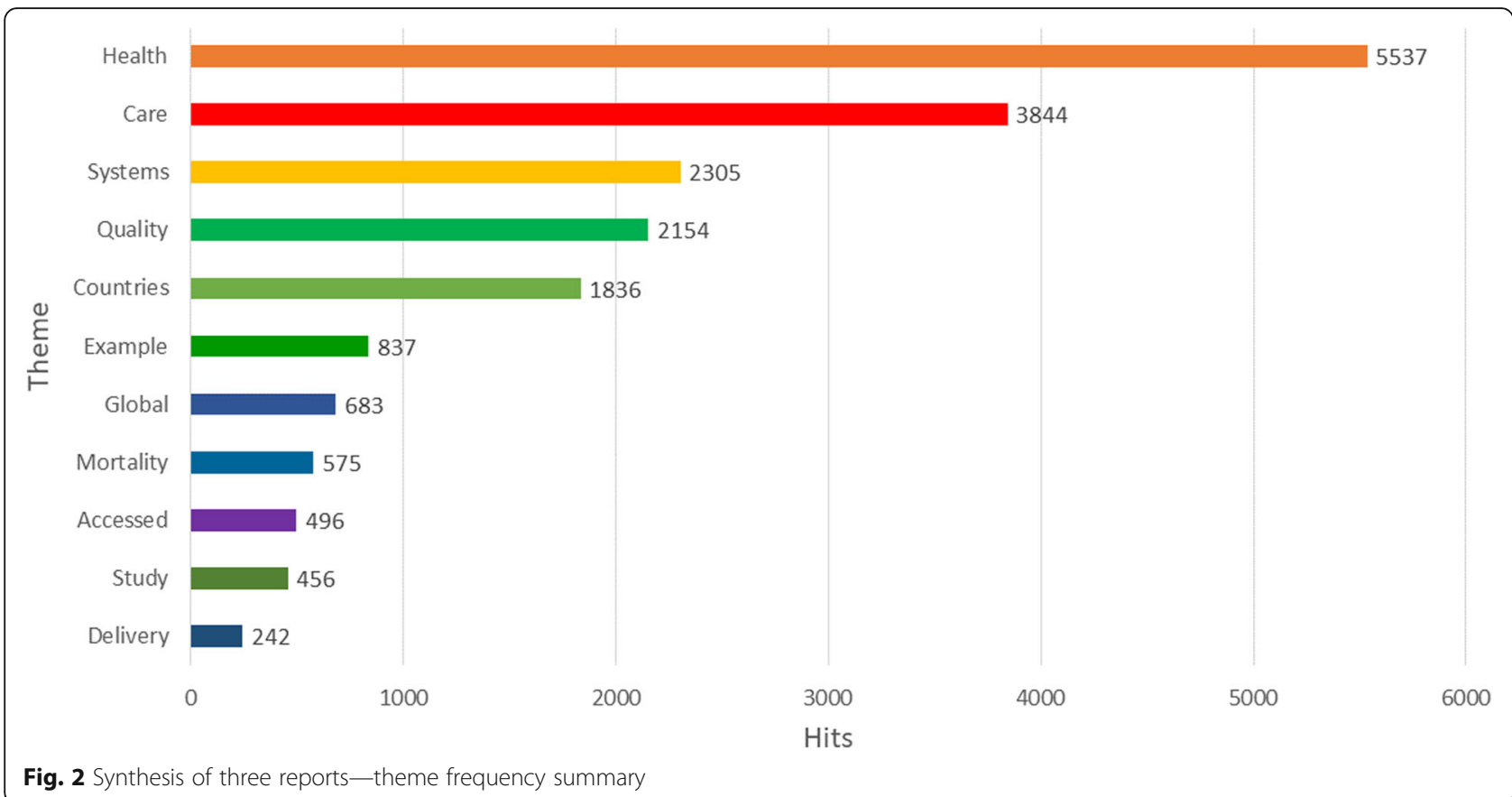

These key themes suggest the report is focused more on providers of care than are the other reports and recommends they offer quality care and effective services to users of health systems.

\section{Discussion}

\section{The reports in context}

Both the Leximancer automated content analyses and our boxed summaries demonstrate that there are more commonalities than differences running through the reports. One intriguing question is why three extraordinarily influential reports in the same domain saw the light in the same year? There are plenty of historical examples of an idea whose time has come. It seems that the thrust of the reports, and their confluence, may signal we have arrived at a crossroads, and the time is ripe to expedite transformational efforts.

Particularly important areas of convergence in these documents are the idea of universal coverage and raising the bar on quality of care and of health systems performance so all citizens in all countries benefit, especially those in the poorest regions. Instead of seeing healthcare in silos (acute settings, community care, general practice, aged care) or in terms of clinical conditions, disease types or specialities (malaria, diabetes, paediatrics), the reports seek coordination and integration of care across the continuum, centred on patients' rather than providers' needs. The reports urge countries to provide incentives in the right place to improve care for best effect. They do not shy away from how complex an undertaking healthcare delivery is and each argues that taking a systems view to problems is critical.

Strategies the reports discern as most useful for improvement include better leadership and governance, judicious and cost-effective use of proven ICT, more training and education for workforces, and applying what is already known, such as via the use of clinical practice guidelines, safe surgical checklists and vaccinations across entire populations for herd immunity. The reports' authors advocate for a patient-based rather than a providerfocused perspective and want those across caring systems to be better at implementation science, translation and disseminating the success exhibited in one setting to others, at scale. Each argues for the importance of measuring progress longitudinally, conducting well-designed evaluation to learn from what is working and what is not, and underpinning improvement efforts with a suitably resourced, purpose-designed research program.

As to differences between the reports and their recommendations, these are surprisingly few, and a matter of degree. The Lancet report focuses on health systems and is more data-rich and researchintensive (there are 327 references cited) and it hones in on saving lives, equity of access and care, measurement of outcomes and transformation of current care systems. The WHO/OECD/World Bank volume links quality improvement to universal health coverage and makes recommendations to four stakeholder groups (governments, health systems, citizens and patients, and healthcare workers), seeking to enrol these groups in the work ahead. 


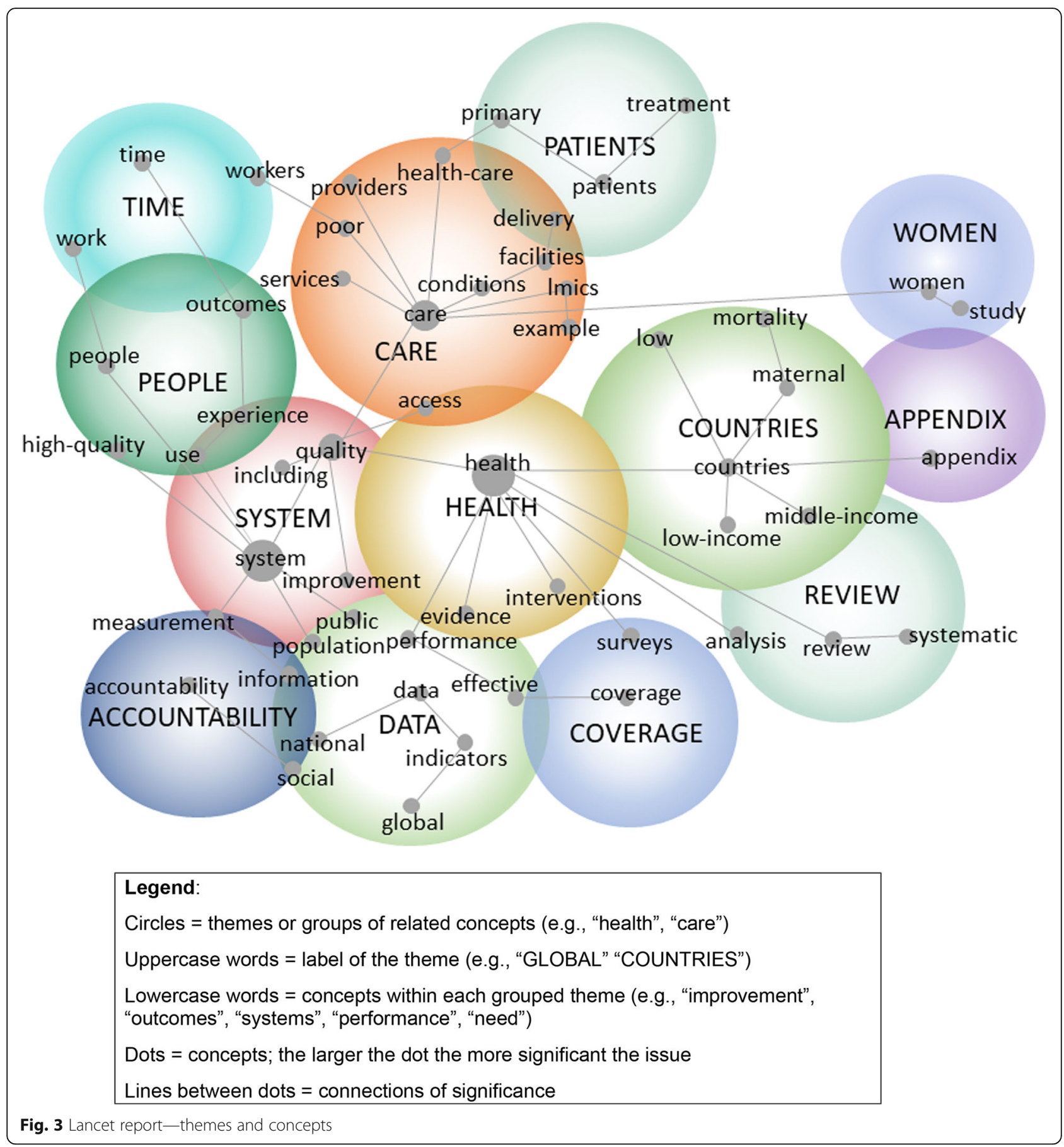

Authors of Crossing the Global Quality Chasm are focused on the six dimensions of quality (safety; effectiveness; person-centredness; accessibility, timeliness, affordability; efficiency; and equity), and take a systems perspective on change, establishing agreed principles for systems redesign and seeking to harness digital progress across countries. They also mount strong arguments for change proponents to focus on informal care and carers, and to reduce corruption.

They all note that poor-quality care remains an entrenched, wicked problem. All-in-all, collectively, the authors of the three volumes challenge those presiding over every health system to lift their game and do better for the benefit over the medium to long term of billions of people. 


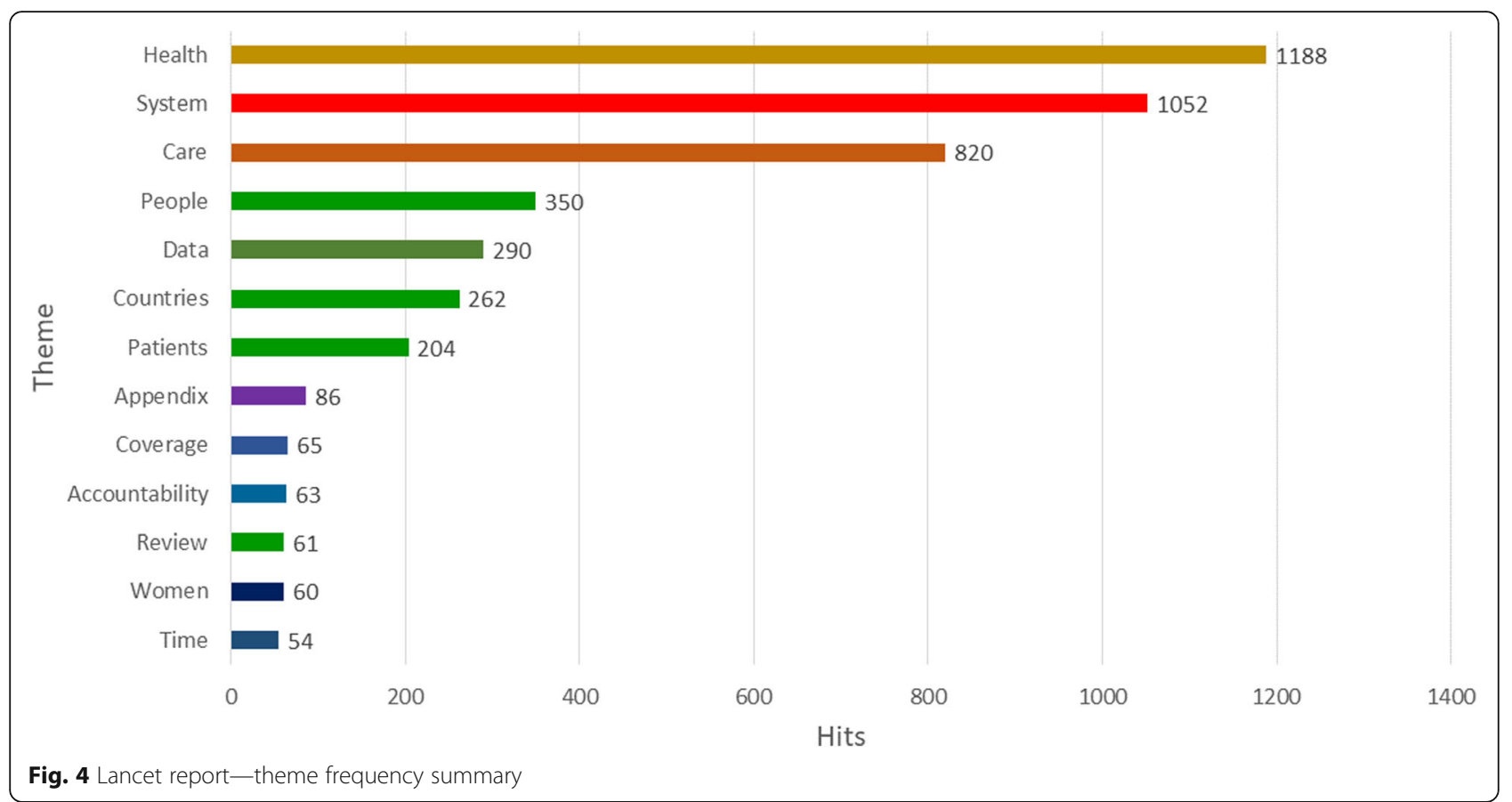

\section{Calling for international action}

How can we move from 2018, the publication year of the reports, to 2020 and beyond, as the decade of action? Going beyond the extensive learnings within these documents, we argue for three calls to action.

\section{Call to action 1: establish a 10-year blueprint for change}

The combined recommendations of the reports will doubtless shape the work of the international community over at least the next 10 years. Yet a very real concern we have is that too often with almost all authoritative reports on health systems reform, whether national, regional or global, much effort is expended on conducting the studies and formulating the recommendations and then the study task force membership dissolves and individuals go back to their normal activities. Less attention is later given to how recommendations might be implemented, translated into learning and adoption strategies, and for political and policy impetus for change to match the importance of the recommendations. We hesitate to call for yet another report to document how to put the recommendations into action; however, we need a blueprint for change and a plan to measure progress. This would articulate, as everything cannot be done simultaneously, the optimal stages to be followed in addressing all the change suggested by the reports, who should do what and with what levels of accountability, and how the interactions between stakeholders will play out. We also need a much clearer idea of how the international community and individual health systems might design rigorous evaluation studies to assess progress and feed that progress back to stakeholders in the system responsible for the improvements. Overall, we must find better ways to document how to disseminate best-practice models, and to achieve improvement at scale, and incorporate these in the blueprint for 2030.

Call to action 2: buy more equitable, high-quality care for the greatest number

Second, collectively the reports plead for every country to move along an improvement gradient; implementation is proposed as a country-level responsibility but with a global commitment, supported by international bodies such as the UN's agencies, the WHO and OECD. So, let us take the word "global", which each of the three contributions uses emblematically and often, seriously. Say we wanted to do the very best we can for the 7.7 billion people in the world, taking what these reports have said to heart, and as a broad framework for change. What is that "very best we can"? It will need to be something that would galvanise the international community and seek to create sufficient leverage for major step-changes in the healthiness of the world.

It seems to us that if we wanted to buy the greatest amount of high-quality care we could, do the most good for the most people and maximise reductions in harm, we would find ways to genuinely divert tangible 


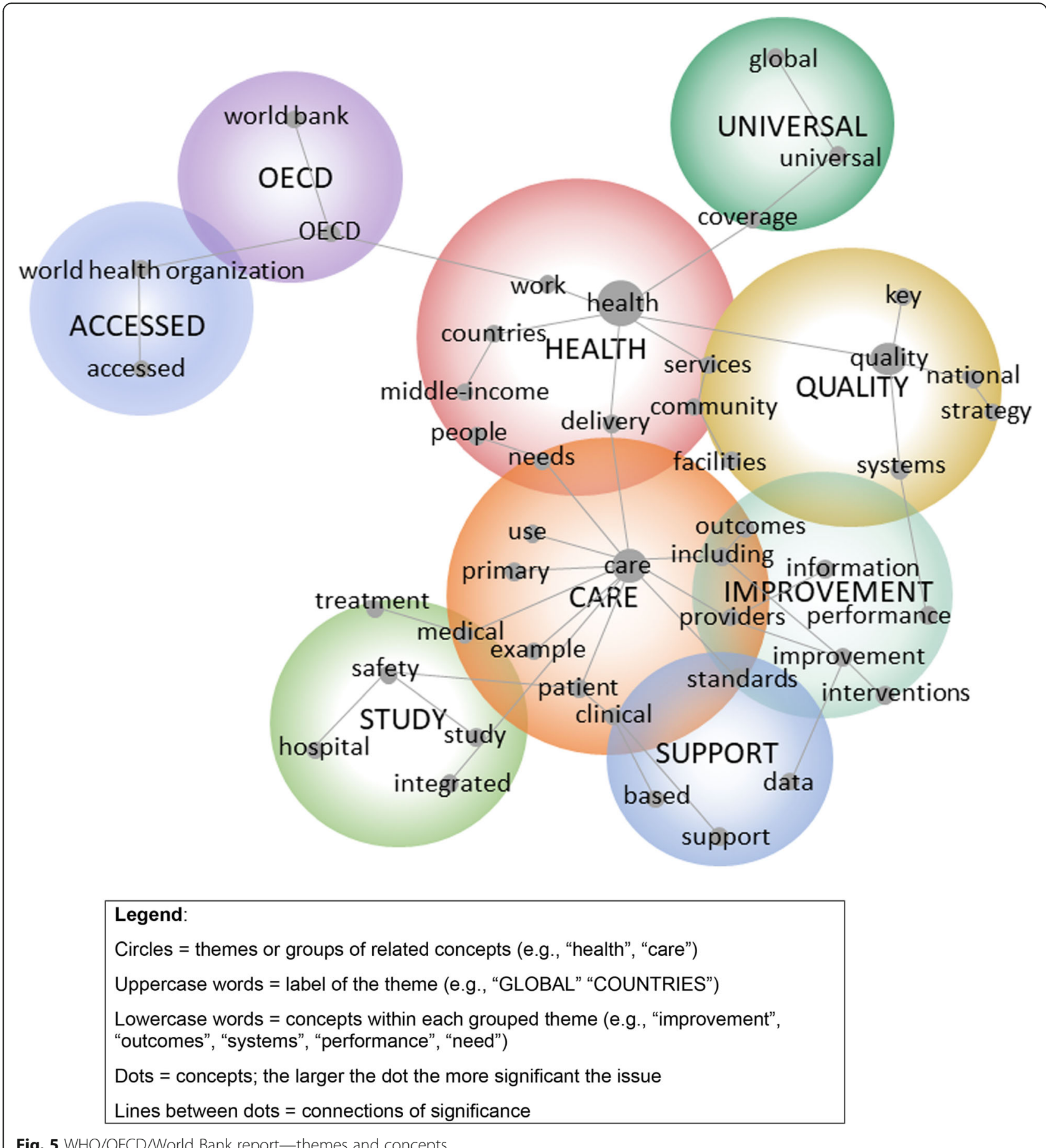

Fig. 5 WHO/OECD/World Bank report-themes and concepts

allocations of money to low- and middle-income health systems. That single action (as hard as it might be to accomplish, as it would mean generating or transferring substantial amounts of funding from the budgets of wealthy countries to less wealthy populations) would reduce inequalities and buy more health gain for more people at the least cost than continuously increasing the spending of GDP on rich health systems already consuming between 10 and $17 \%$ of national income such as the USA, Japan, France and Canada. If we did this, at a stroke we would provide more life-saving, life-enhancing initiatives and could share the advantages of higher-quality care, institute training in continuous improvement, 


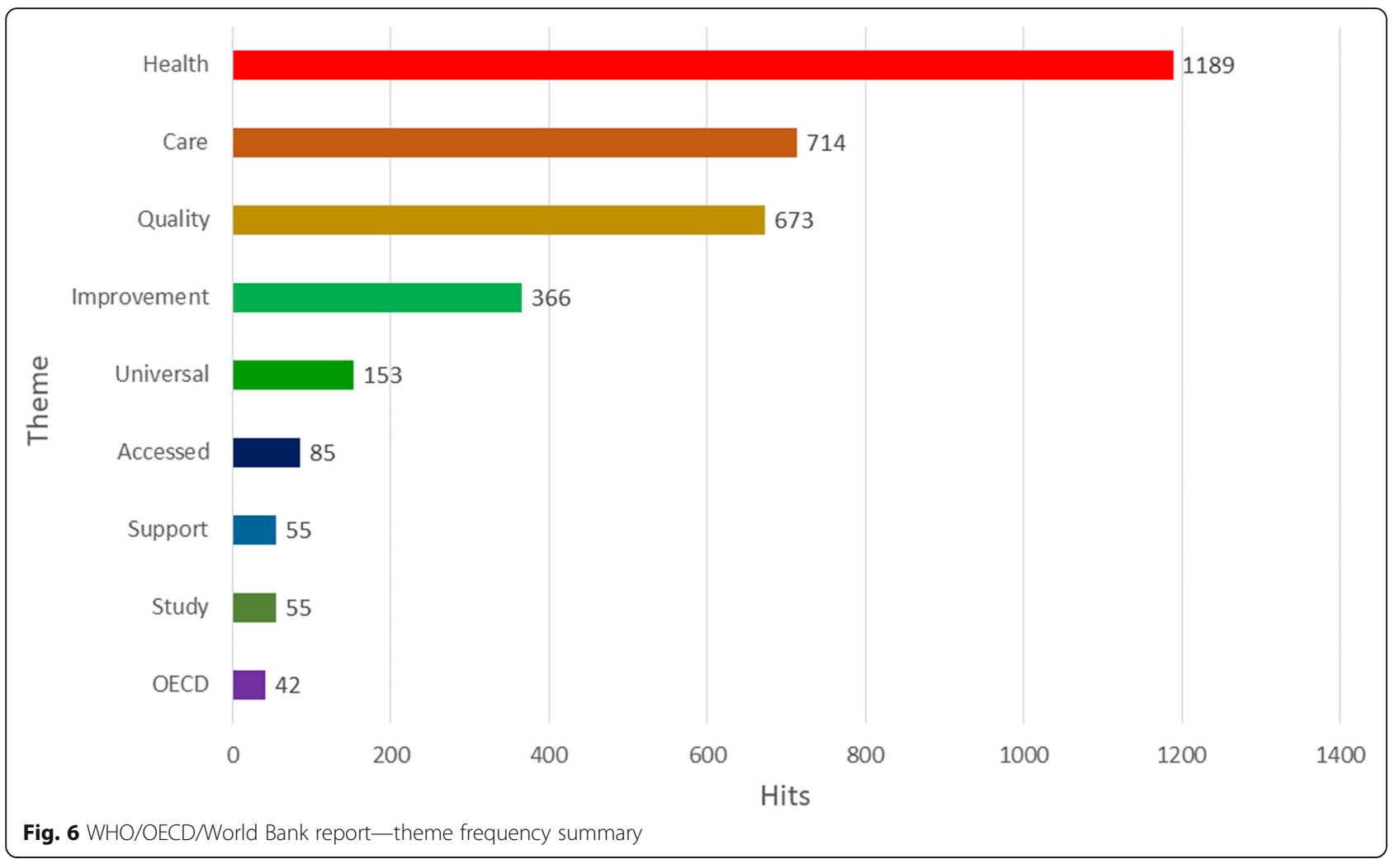

create best-practice patient safety and even mobilise the potential benefits of artificial intelligence in medicine, genomics and modern ICT, to many more people. This could be promoted as an idea whose time has come. Senator Elizabeth Warren of Massachusetts, a prominent United States (US) Democrat who was pitching in 2019 for the 2020 presidential nomination of her party, estimated that just $2 \%$ annual tax on US families with fortunes of over US\$50 million would generate US $\$ 2.75$ trillion over a decade [12]. As this would capture sufficient funding for US student debt forgiveness, and as well two thirds of all US students would receive free college tuition for this amount, imagine the good that could be done if the richest OECD countries did the same and diverted even $1 \%$ annual tax on the wealthy to low-income health systems. We would perhaps generate US $\$ 10$ trillion, which could be put to use, saving lives, providing more care, improving the health of the world and reducing disparities. This would be politically difficult of course, but not impossible.

But even if we did not go this far, by way of illustration, we modelled how much we could generate and potentially divert by allocating just $1 \%$, not of annual tax, but merely of health spending in five wealthy countries, creating a pool of almost US\$50 billion (Table 1) $[13,14]$. We then looked at nine lower-income countries in Africa, Asia and the middle-East and examined the costs of selected programs currently being advanced to make life better, improve quality of care or just to make life bearable (Table 2; synthesised from GlobalGiving) [15]. The costs are so modest compared with the pool of US $\$ 50$ billion that it is virtually impossible to argue against the proposition that we must do something urgently and sustainably to address this level of inequity in some form or another. For so little cost, so much could be gained.

Add initiatives such as these to the new emphasis on integrity in the US's National Academies report, and the need to fight corruption as a new dimension of quality. While we advocate for greater resources, we also call for greater integrity in its application, buttressed by more robust accountability mechanisms.

\section{Call to action 3: learn from what goes right as well as what goes wrong}

Our third call to action leads with the point that all three reports start with the problems in the system: harm, lack of universality and poor-quality care, for example. What they do not recognise sufficiently is that we have not traditionally taken the trouble to learn very well 


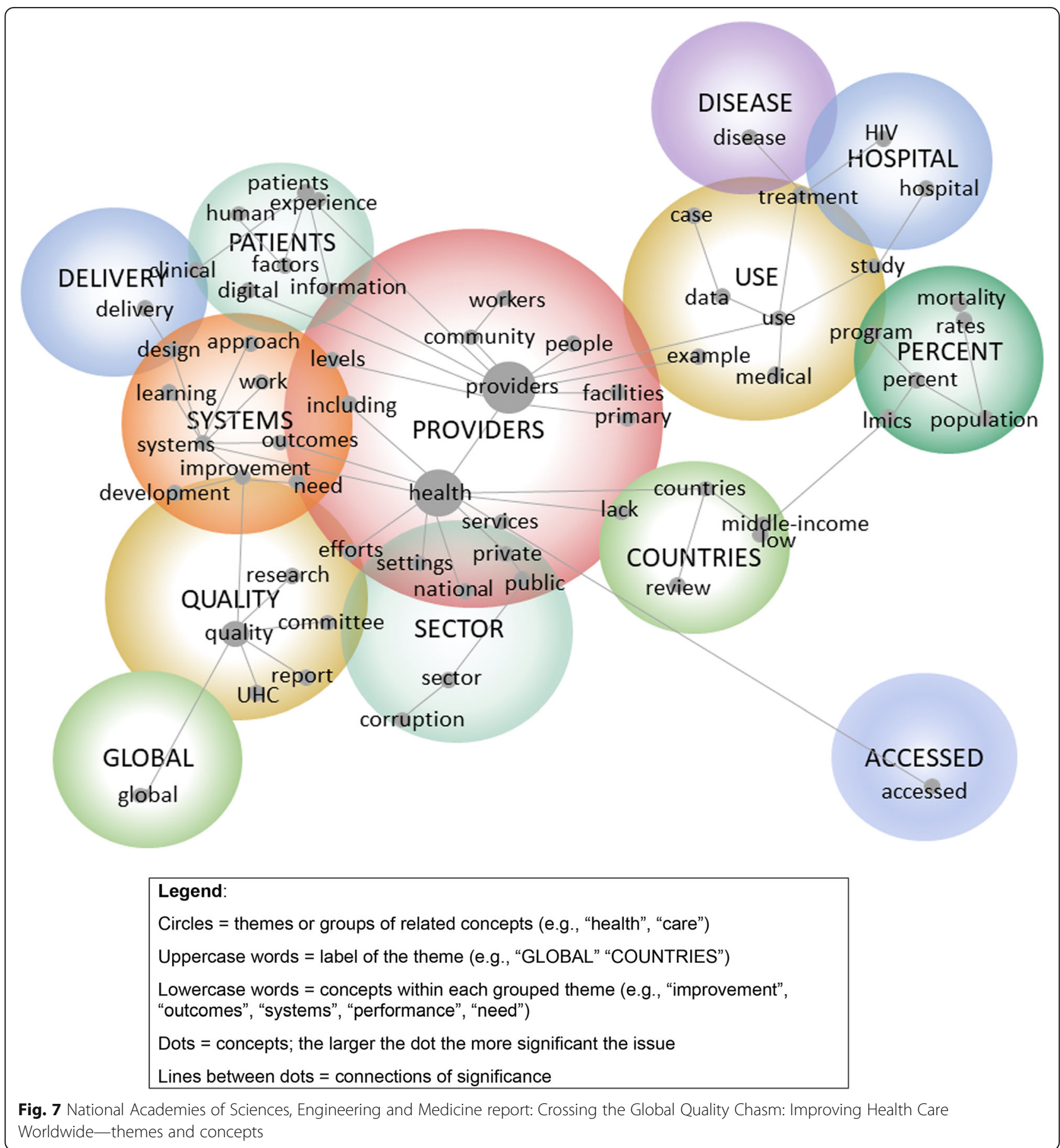

from things going right and to develop ways of supporting this. This perspective, coming from scholars of resilient healthcare and Safety-II, asks not why do things go wrong, but in systems as complex as healthcare (and, as we have seen, in LMIC systems, as resource-deprived), how come so much goes right? Why do some providers, teams and microsystems deal capably with everyday challenges, producing good care despite other providers, teams and microsystems in the same system producing worse outcomes-yet they all face the same constraints? What workarounds are developed by staff to overcome system deficiencies? Lack of resources, poor support systems and less than optimal ICT are all perennial problems every system-even wealthy ones-faces. Traditionally, change agents and quality and safety advocates have been more interested in stamping out harm than extending 


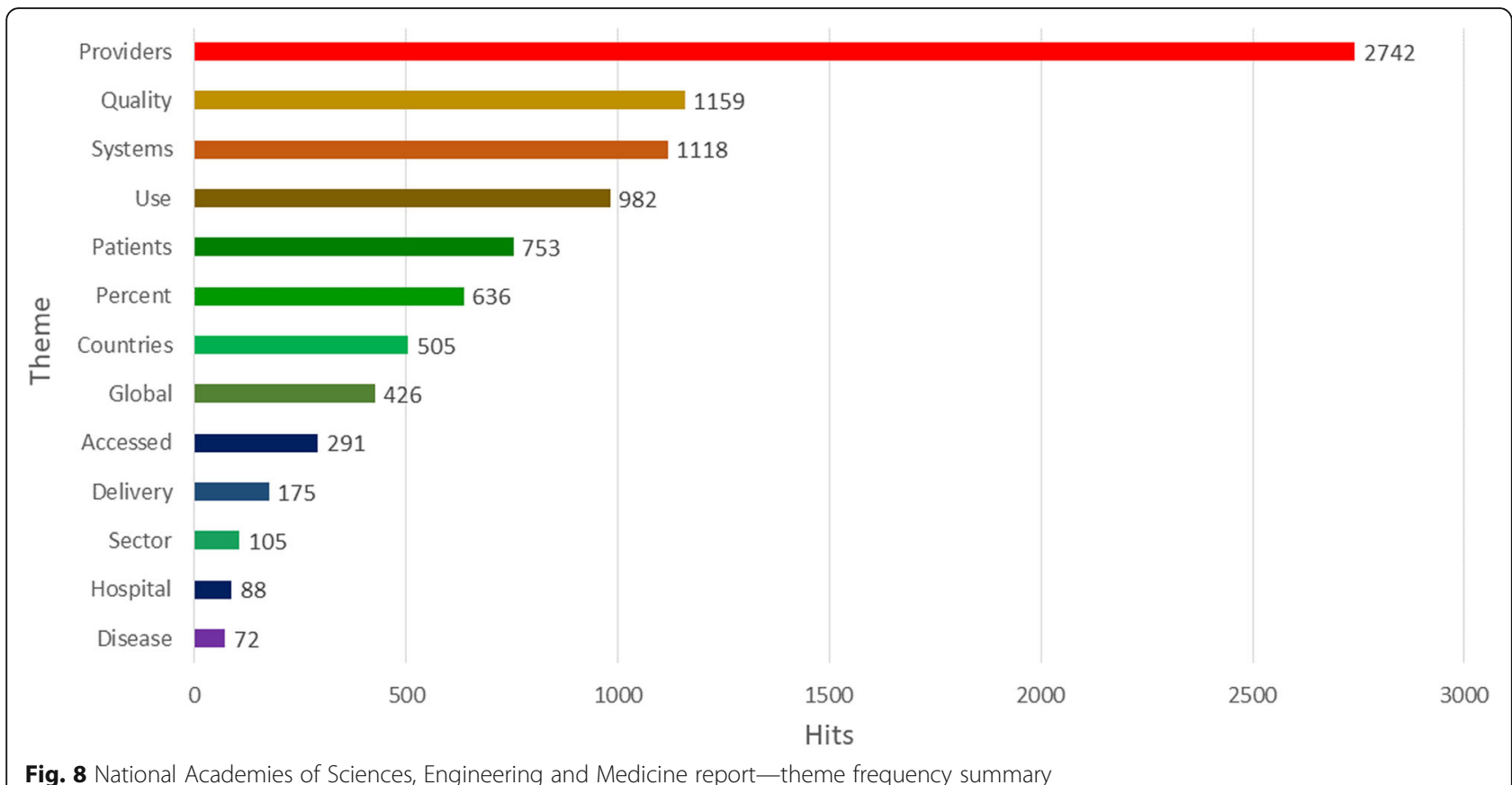

understanding of what systems do in their entirety, good and bad, and how the work force adopts, coordinates and shares knowledge to keep patients safe and provide quality care. So running alongside the ideas and recommendations from these three reports, we argue we need exemplar studies of success-building, for instance, on the publication of recent case study exemplars [18]. Table 3 presents eight of these examples, by way of indicating the potential for implementable change at the country level, from a platform of prior successes. The Table shows how every country has something to offer other health systems in improvement and reform.

We propose the creation of a database of successful case studies and learnings from things going right, built from the combined experience of the major international bodies (e.g. ISQua, WHO, World Bank, OECD). Specific country experiences with national- or regional-level programs, projects or interventions, with details of what works, for whom and under what conditions, would be of substantial benefit to others grappling with similar problems. And this takes us back to call to the first call to action-we need a persuasive blueprint for change, including allocating responsibilities for mining and using such information.

\section{Strengths and weaknesses of the calls to action}

Although they are pitched at a high level, these three calls to action represent initiatives that, if adopted, could help galvanise the international community. The strengths of such a set of change ideas are that they are built from the reports themselves, and other international suggestions for change over the years [19-23]. As to weaknesses, it is recognised that the approaches

Table 1 Wealth generated from 1\% of per capita health spending in five selected OECD countries [13, 14]

\begin{tabular}{llllc}
\hline High-Income Country & $\begin{array}{l}\text { Health spending } \\
\text { (US dollars/capita), } \\
\text { per annum }\end{array}$ & $\begin{array}{l}\text { 1\% of health spending in } \\
\text { high-income countries } \\
\text { (US dollars/capita), per annum }\end{array}$ & Population & Total (\$US rounded) \\
\hline USA & $\$ 10,586.08$ & $\$ 105.86$ & $327,167,434$ & $\$ 34,633,944,563$ \\
Japan & $\$ 4,766.07$ & $\$ 47.66$ & $126,529,100$ & $\$ 6,030,376,906$ \\
UK & $\$ 4,069.57$ & $\$ 40.69$ & $66,488,991$ & $\$ 2,705,437,044$ \\
Germany & $\$ 5,986.43$ & $\$ 59.86$ & $82,927,922$ & $\$ 4,964,065,411$ \\
Australia & $\$ 5,005.32$ & $\$ 50.05$ & $24,992,369$ & $\$ 1,250,868,068$ \\
Total & & & $\$ \mathbf{4 9}, \mathbf{5 8 4 , 6 9 1 , 9 9 2}$ \\
\hline
\end{tabular}


Table 2 Life-sustaining or quality-of-care-enhancing programs in nine selected lower-income countries [15-17]

\begin{tabular}{|c|c|c|}
\hline $\begin{array}{l}\text { Low-income } \\
\text { Country [14] }\end{array}$ & Types of initiatives & Cost (\$US) of program \\
\hline \multirow[t]{2}{*}{ Afghanistan } & Training midwives in Afghanistan. & \multirow{2}{*}{$\begin{array}{l}\mathbf{\$ 5 0 , 0 0 0} \text { (e.g. } \$ 600 \text { contributes to the } \\
\text { development of three training modules to train } \\
100 \text { midwives each) }\end{array}$} \\
\hline & $\begin{array}{l}\text { As a preventative approach to the high maternal and infant mortality rates in } \\
\text { Afghanistan, this initiative funds midwifery training to improve equity and access } \\
\text { to essential women's healthcare in rural areas. }\end{array}$ & \\
\hline \multirow[t]{2}{*}{ Burundi } & Providing healthcare to 1000s in Bujumbura slum. & \multirow{2}{*}{$\begin{array}{l}\mathbf{\$ 2 0 , 0 0 0} \text { (e.g. } \$ 300 \text { funds a 3-day trauma healing } \\
\text { workshop for gender-based violence survivors) }\end{array}$} \\
\hline & $\begin{array}{l}\text { Funds healthcare support, trauma healing workshops and AIDS testing to the } \\
\text { Ntaseka Clinic, for more than } 5000 \text { people per annum. Patients include survivors } \\
\text { of gender-based violence and abuse, people who are HIV positive, and the gen- } \\
\text { eral population. }\end{array}$ & \\
\hline \multirow[t]{2}{*}{ Chad } & Life skills and peer education for Chadian Youth. & \multirow{2}{*}{$\begin{array}{l}\$ 33,913 \text { (e.g. } \$ 200 \text { supports one community } \\
\text { outreach even in N'Djamena) }\end{array}$} \\
\hline & $\begin{array}{l}\text { Funds quality programs to the Chadian youth; the programs which are peer- } \\
\text { based, disseminate information about the risks of drugs, alcohol, and transmission } \\
\text { of HIV/AIDS. }\end{array}$ & \\
\hline \multirow[t]{2}{*}{ Ethiopia } & Simple surgery to restore sight to Ethiopians. & \multirow{2}{*}{$\begin{array}{l}\$ 6000 \text { (e.g. } \$ 12 \text { funds the cost to conduct two } \\
\text { eye surgeries to reverse the effects of blinding } \\
\text { trachoma) }\end{array}$} \\
\hline & $\begin{array}{l}\text { Funds simple eye surgeries in Ethiopia, including remote Ethiopia, for those } \\
\text { suffering from trachoma. The hope is to eradicate the eye disease. }\end{array}$ & \\
\hline \multirow[t]{2}{*}{ Liberia } & Restoring healthcare to women and girls in Liberia. & \multirow{2}{*}{$\begin{array}{l}\$ 100,000 \text { (e.g. } \$ 1500 \text { pays all clinic operating } \\
\text { costs in Liberia for a month) }\end{array}$} \\
\hline & $\begin{array}{l}\text { Funds community-based preventative care and an acute care clinic in Kakata to } \\
\text { women and girls in Margibi County, Liberia. The clinic provides emergency care } \\
\text { and has over 200,000 patients. }\end{array}$ & \\
\hline \multirow[t]{2}{*}{ Malawi } & End mother to child transmission of HIV in Malawi. & \multirow{2}{*}{$\begin{array}{l}\text { \$5000 (e.g. \$2 can pay for } 1500 \text { text messages } \\
\text { to support and educate adolescents on HIV and } \\
\text { safe sex) }\end{array}$} \\
\hline & $\begin{array}{l}\text { This is the largest country program, and the first that employs and recruit's HIV } \\
\text { positive men as Expert Clients. There are over } 270 \text { Expert Clients in } 98 \text { clinics who } \\
\text { support and educate other men in the area about HIV. }\end{array}$ & \\
\hline \multirow[t]{2}{*}{ Nepal } & Rescue children suffering from severe malnutrition. & \multirow{2}{*}{$\begin{array}{l}\mathbf{\$ 5 0 , 0 0 0} \text { (e.g. } \$ 10 \text { gives medicine to one child } \\
\text { while they are restored to health at a Nutritional } \\
\text { Rehabilitation Home) }\end{array}$} \\
\hline & $\begin{array}{l}\text { "Fifty percent of Nepali children under five-years-old are malnourished ... Malnu- } \\
\text { trition is the main cause of death for as many as } 50,000 \text { Nepali children each year." } \\
\text { This program funds Nutritional Rehabilitation homes to restore the health of child } \\
\text { and educate parents of the risks. }\end{array}$ & \\
\hline \multirow[t]{2}{*}{ Tanzania } & Make motherhood safe for Tanzanian women. & \multirow{2}{*}{$\begin{array}{l}\mathbf{\$ 4 0 0 , 0 0 0} \text { (e.g. } \$ 1000 \text { funds a C-section and } \\
\text { recovery) }\end{array}$} \\
\hline & $\begin{array}{l}\text { Funds the construction, equipment and training of staff for a new maternity } \\
\text { hospital in Dar es Salaam, Tanzania. There will be } 22 \text { facilities and a 200-bed hos- } \\
\text { pital to improve maternal health and assist with decreasing the high maternal } \\
\text { mortality rate in Tanzania. }\end{array}$ & \\
\hline \multirow[t]{2}{*}{ Uganda } & Stop Ugandan women and children dying at childbirth. & \multirow{2}{*}{$\begin{array}{l}\$ 36,000 \text { (e.g. } \$ 4200 \text { will buy one portable } \\
\text { ultrasound scanning (Clarius) machine from the } \\
\text { USA.) }\end{array}$} \\
\hline & $\begin{array}{l}\text { Funds maternal health and welfare in Uganda and increases the quality of care for } \\
\text { women in childbirth through effective equipment, training of midwives, social } \\
\text { workers and radiographers and supporting outreach programs. }\end{array}$ & \\
\hline
\end{tabular}

[Source: GlobalGiving [15]]

we are suggesting may not receive sufficient attention in the present pandemic era. The current pandemic itself raises serious questions about health system resilience and the quality of Covid-19 and routine non-Covid-19 care. The Covid-19 pandemic amplifies the need for health system strengthening to address gnawing quality of care gaps that have intensified in the wake of the global crisis. Regarding the second call, rather than wait for resources to be released from the benevolence of rich countries, the Covid-19 pandemic teaches that it is time for resource-constrained countries to reprioritize health resource allocation. Ghana, for example, has demonstrated this through activation of local manufacturing of personal protective equipment.

That being said, development of a blueprint for action with a clear picture of what healthcare in 2030 should look like is possible; the funding required for call to action 2, despite the good it could bring to the world, may not be given priority by wealthy health systems; and call to action 3, more thoroughly understanding health systems from a systems standpoint and learning from things going right is increasingly receiving attention [24-28], yet has not yet become a mainstream idea. While these recommendations are for the long term, 


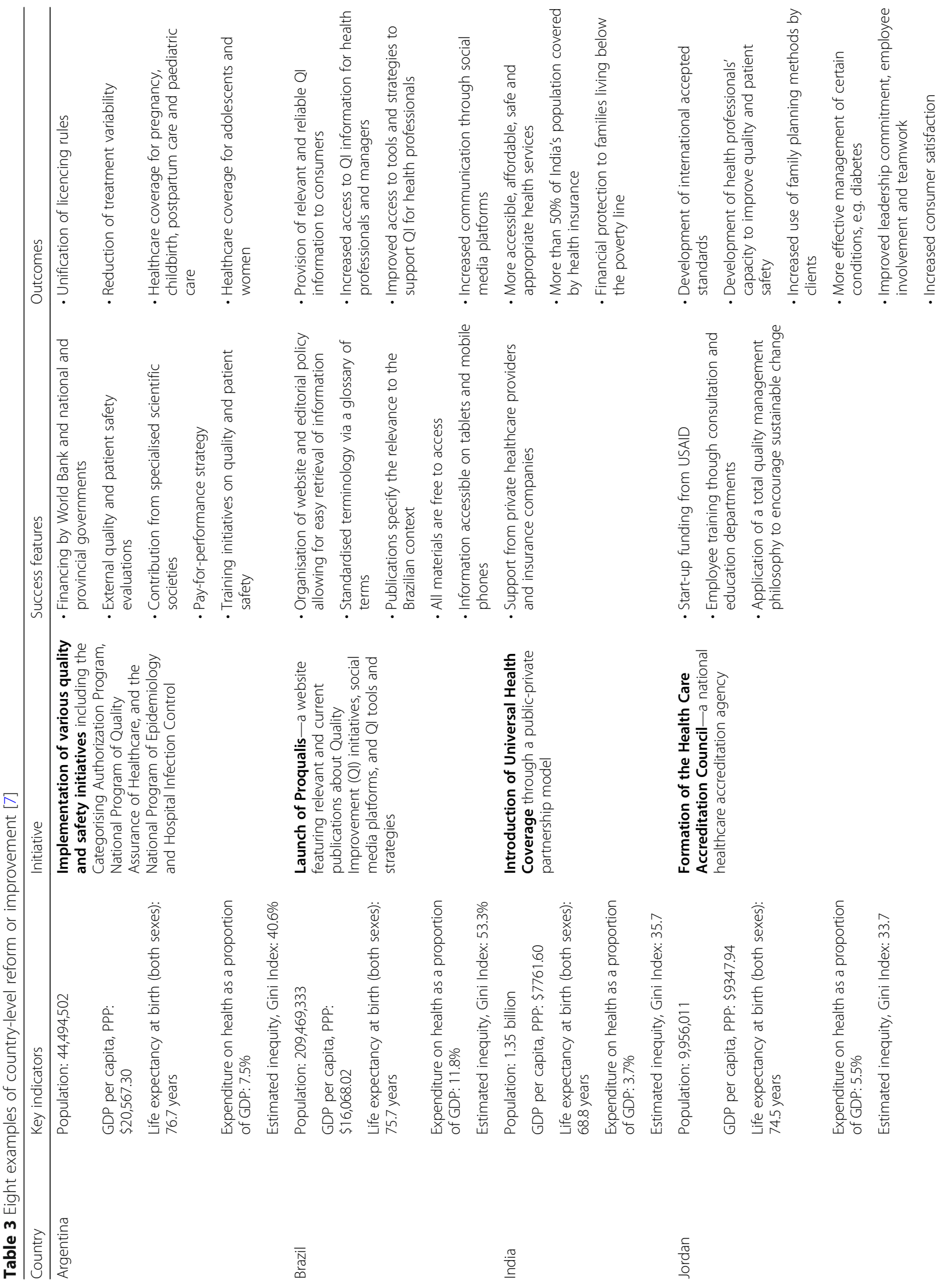




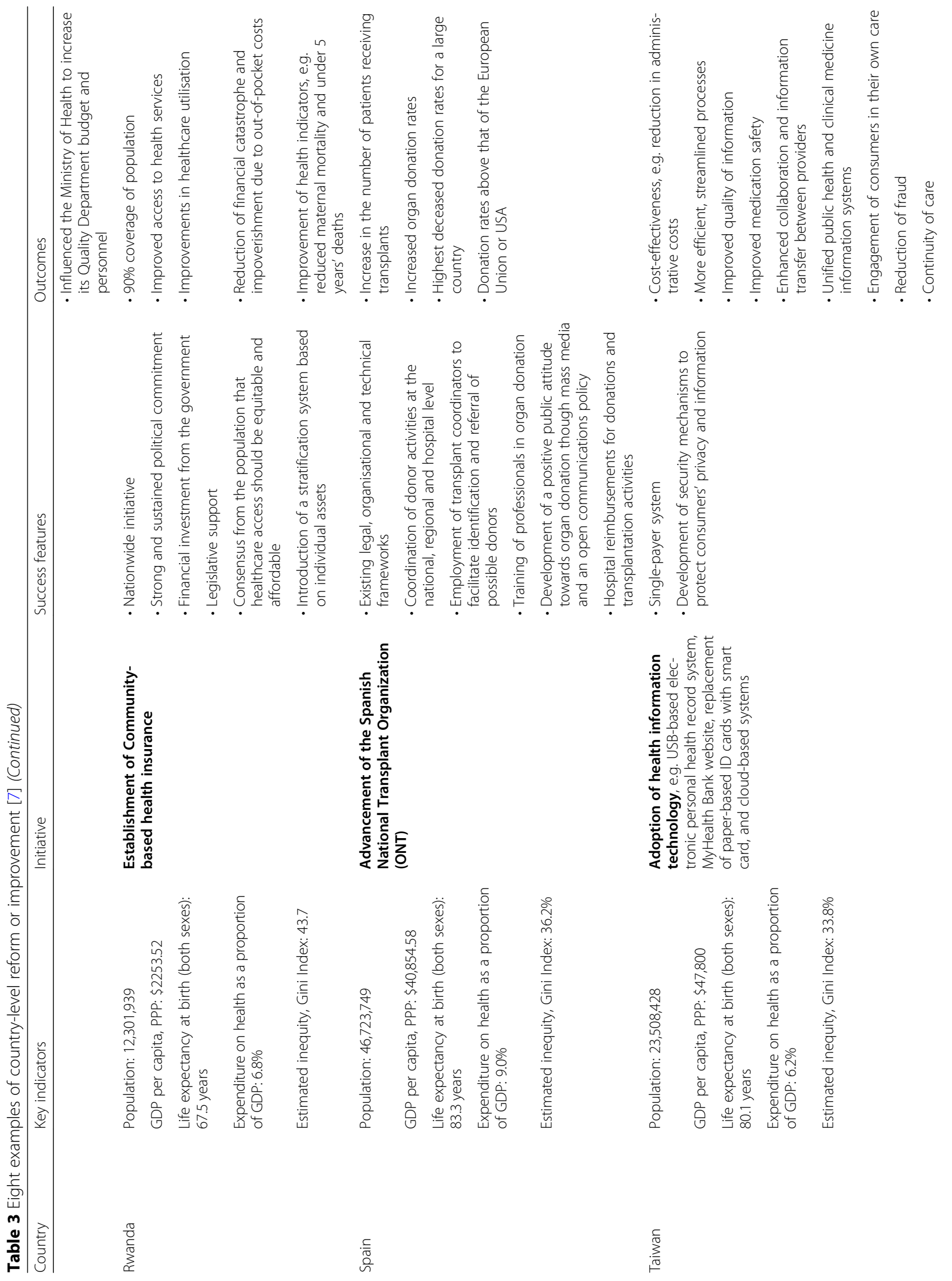




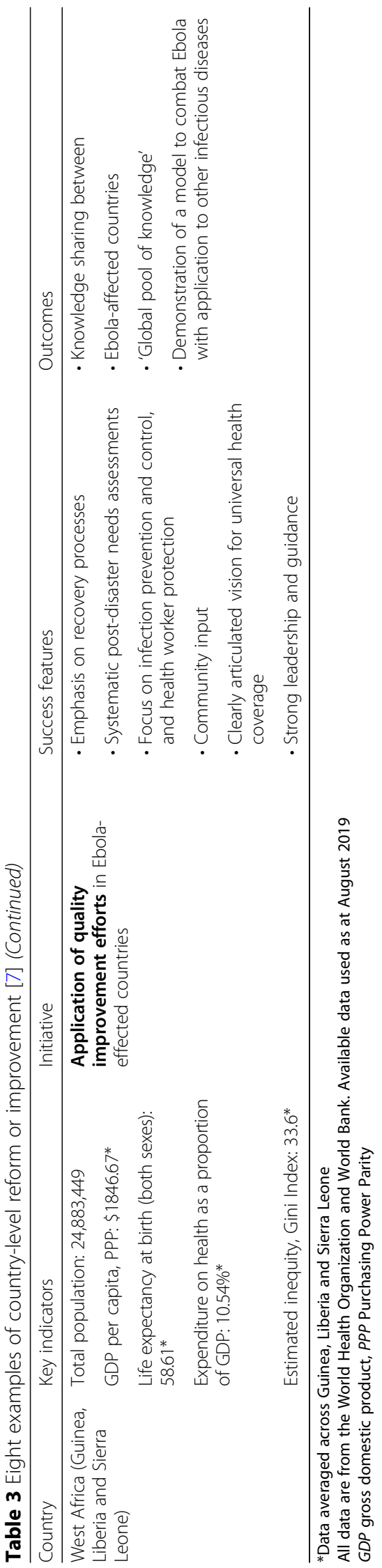


determination and a willingness to begin, even during a pandemic, are essential. Who has the courage to take the lead?

\section{Conclusion}

If we actioned these calls to arms over the decade of the 2020s, and move the reports' proposals into the real world with a template for change which synthesises and incorporates their recommendations, we might find ourselves on a path to progress in a strategic rather than piecemeal or fragmented way. And the potential benefits to humankind, of putting our money where our mouth is, galvanising the world's expertise into an actionable plan, buying better care for less fortunate populations and more thoroughly understanding the whole caring enterprise, building on past success? These would be enormous.

\section{Abbreviations}

C-section: Caesarean section; GDP: Gross domestic product; HIV: Human immunodeficiency viruses; IAQS: International Academy of Quality and Safety; ICT: Information and Communications Technology; ID: Identity document; ISQua: International Society for Quality in Health Care; LMICs: Low- and middle-income countries; OECD: The Organisation for Economic Co-operation and Development; ONT: National Transplant Organization; PPP: Purchasing power parity; QI: Quality improvement; UHC: Universal health coverage; UN: United Nations; US: United States; USAID: United States Agency for International Development; USBbased: Universal serial bus based; WHO: World Health Organization

\section{Acknowledgements}

We would like to thank and acknowledge research assistants Ms. Meagan Warwick, Ms. Kristiana Ludlow, Ms. Chiara Pomare, Dr. Kathryn Gibbons and Ms. Kelly Nguyen for their editorial and research assistance.

\section{Authors' contributions}

$J B, C V$ and DWB conceptualised the manuscript. All authors were part of the analysis, drafting and finalisation of the manuscript. The authors read and approved the final manuscript.

\section{Funding}

$\mathrm{JB}$ is Professor of Health Systems Research and Founding Director of the Australian Institute of Health Innovation at Macquarie University, Sydney, Australia. This work was supported by the Australian Institute of Health Innovation which receives $80 \%$ of its core funding from category one, peer-reviewed grants, chiefly, the National Health and Medical Research Council (NHMRC) and Australian Research Council (ARC) funding which includes the NHMRC Partnership Grant for Health Systems Sustainability (ID: 9100002).

\section{Availability of data and materials}

The datasets used and/or analysed during the current study are available from the corresponding author on reasonable request.

\section{Ethics approval and consent to participate}

Not applicable.

\section{Consent for publication}

Not applicable.

\section{Competing interests}

None to declare.

\section{Author details}

${ }^{1}$ Centre for Healthcare Resilience and Implementation Science, Australian Institute of Health Innovation, Macquarie University, Level 6, 75 Talavera road, North Ryde, NSW 2113, Australia. 'Department of Experimental Psychology,
University of Oxford, Oxford OX2 6GG, UK. ${ }^{3}$ Institute for Clinical Effectiveness and Health Policy (IECS), Viamonte 2146 - 3 Piso, C1056ABH Ciudad de, Buenos Aires, Argentina. ${ }^{4}$ Graduate School of Medicine and Faculty of Medicine, Yoshida-Konoe-cho, Sakyo-ku, Kyoto University, Kyoto 606-8501, Japan. ${ }^{5}$ International Society for Quality in Health Care (ISQua), Huguenot House, Dublin D02 NY63, Ireland. ${ }^{6}$ Institute for Healthcare Improvement, Boston, MA 02109, USA. ${ }^{7}$ Harvard Medical School, Boston, MA 02115, USA.

Received: 6 May 2020 Accepted: 6 August 2020

Published online: 29 October 2020

\section{References}

1. National Academics of Sciences, Engineering and Medicine. Crossing the global quality chasm: improving health care worldwide. Washington, DC: The National Academies Press; 2018.

2. World Health Organization, Organisation for Economic Co-Operation and Development, and The World Bank. Delivering quality health services: a global imperative for Universal Health Coverage. Washington, DC: WHO, OECD, World Bank; 2018.

3. Kruk ME, Gage AD, Arsenault C, Jordan K, Leslie HH, Roder-DeWan S, et al. High-quality health systems in the sustainable development goals era: time for revolution. Lancet Glob Health Comm High Qual Health Syst SDG Era. 2018;6:PE1196-E252.

4. Le Fanu R. The rise and fall of modern medicine. New York: Ingram Publishing Services; 2012.

5. Riley D, Hao JJ, Kiene H, Kienle G, Mittelman M, Plotnikoff GA. Global advances in health and medicine. Glob Adv Health Med. 2012;1(1):5-6.

6. Mills A. Health care systems in low- and middle-income countries. N Engl J Med. 2014;370(6):552-7.

7. Braithwaite J, Mannion R, Matsuyama Y, Shekelle P, Whittaker S, Al-Adawi S, editors. Healthcare systems: future predictions for global care. Boca Raton: CRC Press; 2018

8. Braithwaite J, Churruca K, Ellis LA, Long J, Clay-Williams R, Damen N, et al. Complexity science in healthcare - aspirations, approaches, applications and accomplishments: a white paper. Sydney: Australian Institute of Health Innovation, Macquarie University; 2017.

9. Watson M, Smith A, Watter S. Leximancer concept mapping of patient case studies. In: Khosla R, Howlett RJ, Jain LC, editors. Knowledge-based intelligent information and engineering systems, vol. 3683. Berlin, Heidelberg: Springer; 2005.

10. Lamprell G, Braithwaite J. Mainstreaming gender and promoting intersectionality in Papua New Guinea's health policy: a triangulated analysis applying datamining and content analytic techniques. Int J Equity Health. 2017;16:65.

11. Nunez-Mir GC, lannone BV III, Pijanowski BC, Kong N, Fei S. Automated content analysis: addressing the big literature challenge in ecology and evolution. Methods Ecol Evol. 2016;7:1262-72.

12. Qui L. Fact-checking Elizabeth Warren on the campaign trail. New York: New York Times; 2019.

13. Organisation for Economic Co-Operation and Development. Health spending (indicator). 2018. https://data.oecd.org/healthres/health-spending. htm. Accessed 7 July 2020.

14. The World Bank. Population, total. 2018. https://data.worldbank.org/ indicator/sp.pop.totl. Accessed 7 July 2020.

15. Global Giving. Health - explore projects. 2019. https://www.globalgiving.org/ search/?size $=10 \&$ nextPage $=1 \&$ sortField $=$ sortorder\&selectedThemes $=$ health\&loadAllResults=true. Accessed 7 July 2020.

16. The World Bank. World Bank country and lending groups. 2019. https:// datahelpdesk.worldbank.org/knowledgebase/articles/906519-world-bankcountry-and-lending-groups. Accessed 7 July 2020

17. The World Bank. Current health expenditure (\% of GDP). 2019. https:// data.worldbank.org/indicator/SH.XPD.CHEX.GD.ZS?locations=XM. Accessed 7 July 2020.

18. Braithwaite J, Mannion R, Matsuyama Y, Shekelle P, Whittaker S, Al-Adawi S, editors. Health systems improvement across the globe: success stories from 60 countries. Boca Raton: CRC Press; 2018.

19. Braithwaite J, Mannion R, Matsuyama Y, Shekelle PG, Whittaker S, Al-Adawi S, et al. The future of health systems to 2030: a roadmap for global progress and sustainability. Int J Qual Health Care. 2018;30(10):823-31.

20. Clements BJ, Coady D, Gupta S, editors. The economics of public health care reform in advanced and emerging economies. Washington DC: International Monetary Fund; 2012. 
21. Ranade W. Markets and health care: a comparative analysis. Oxon: Routledge; 2018.

22. World Health Organization. Strategizing national health in the 21st century: a handbook. WHO. 2016. https:/www.who.int/publications/i/item/strategizingnational-health-in-the-21st-century-a-handbook. Accessed 7 July 2020.

23. de Looper M, Lafortune G. Measuring disparities in health status and in access and use of health care in OECD countries. OECD health working papers, no. 43. Paris: OECD Publishing; 2009. https://doi.org/10.1787/ 225748084267. Accessed 7 July 2020.

24. Hollnagel E, Braithwaite J, Wears RL, editors. Resilient health care. Farnham: Ashgate Publishing; 2013.

25. Wears RL, Hollnagel E, Braithwaite J. Editors. Resilient health care volume. 2: the resilience of everyday clinical work. Farnham: Ashgate Publishing; 2015.

26. Braithwaite J, Wears RL, Hollnagel E, editors. Resilient health care volume 3 : reconciling work-as-imagined and work-as-done. Abingdon: Taylor \& Francis; 2017.

27. Hollnagel E, Braithwaite J, Wears RL. Resilient health care volume 4: delivering resilient health care. Abingdon: Routledge: Taylor \& Francis Group; 2018.

28. Braithwaite J, Hollnagel E, Hunte GS. Resilient health care volume 5: working across boundaries. Boca Raton: Routledge: Taylor \& Francis Group; 2019.

\section{Publisher's Note}

Springer Nature remains neutral with regard to jurisdictional claims in published maps and institutional affiliations.

Ready to submit your research? Choose BMC and benefit from:

- fast, convenient online submission

- thorough peer review by experienced researchers in your field

- rapid publication on acceptance

- support for research data, including large and complex data types

- gold Open Access which fosters wider collaboration and increased citations

- maximum visibility for your research: over $100 \mathrm{M}$ website views per year

At $\mathrm{BMC}$, research is always in progress.

Learn more biomedcentral.com/submissions 